\title{
A Taxonomy of Secondary School Athletic Team Names and Mascots in the United States
}

\author{
Ezra J. Zeitler (1)
}

\section{Department of Geography a Anthropology, University of Wisconsin- Eau Claire, Eau Claire, WI, USA}

Athletic team names are a fascinating yet understudied topic in onomastics. Inspired by the work of Nuessel (1994) and Smith (1997) and framed by the extensive toponymy approach described by Tent (2015), this study proposes a taxonomy of team names and mascots used by high schools in the United States. A list of 20,853 schools procured from the Clell Wade Coaches Directory catalyzed the study, and content analysis of school websites and social media accounts determined the mascots of ambiguous team names. The results include seven general categories: humans, fauna, flora, inanimate objects and phenomena, deities and spiritual beings, mythological creatures and beings, and schools not using team names. Most schools use an animal or human mascot, and prevailing themes among all names include a strong degree of convention in their selection, a high frequency of bellicosity in their character, and a small but notable observance of local distinctiveness in their presence.

KEYWORDS team names, mascots, high schools, toponymy, taxonomy

\section{Introduction}

Team names used by secondary schools to represent the interscholastic activities of its students is an understudied topic in onomastics. Nuessel's (I994) seminal examination of race, gender, and religious-based team names included a nationwide analysis at professional and collegiate levels and a case study of their use in Illinois and Indiana high schools. Smith's (1997) insightful analysis of team names used by high schools in Washington State includes a taxonomic classification based on the degree of violence the name implies and considers the degree to which they carried derogatory meanings to historically marginalized racial/ ethnic groups, social groups, or individuals. Zeitler and Petzold (200I) 
employed a mixed-methods approach to classifying and describing the origins of 422 public secondary school team names in Wisconsin. Their geographic framework identified schools that incorporated local economic activities, demography, historical geography, and physio-environmental characteristics into their team names. A small group of passionate high school team name enthusiasts in Texas (Barlow et. al 2005; Sledge 2005), Illinois (Willman 2005) and Indiana (Houck 2003) have published books for a general audience that include origin stories for team names within their respective states. Houck's (2013) similar work of approximately I,000 discrete team names in the United States is the most impressive work on this topic. These books reveal the rich stories of team names on a case-by-case basis but do not analyze trends or patterns in team name use.

This study contributes to the body of onomastic knowledge through an examination of 20,883 high school team names and mascot imagery at a national level. Tent (2015) describes this type of analysis as extensive toponymy, a research approach that involves the quantitative analysis of large datasets. The absence of a comprehensive nationwide study of secondary school team names and mascots, to date, is understandable. The sheer number of schools, lack of centralized databases in some states, and time required to collect names makes accumulation prohibitive. State interscholastic athletic and activities associations are great resources as they often provide online directories of schools, but team names are not always listed. This study circumvented these issues through the purchase of a privately produced, national database published by the Clell Wade Coaches Directory. The primary market for this decades-old and annually updated database is college athletic recruiters who use it, as the directory's name implies, to contact the coaches of high school athletic teams. The directory also includes general school information, including enrollment numbers, team names, and school colors (Clell Wade Coaches Directory 2016).

Three terms-team name, mascot, and logo-are often used synonymously to describe a team, but each refers to a distinct characteristic of a team's textual and visual representation (Nuessel I994). The team name (colloquially called a nickname) refers to the linguistic name (or names) of a team. The term mascot refers to a three-dimensional living, costumed, or inanimate representation of the team name. In a handful of cases, the mascot does not match the moniker (i.e. the Berries of Logansport, Indiana use Felix the Cat of comic book fame as its mascot). Finally, a team's logo refers to a static, visual representation of the team name and/or mascot.

\section{Team Names and Place Identity}

Just as place names originate from the need or desire to distinguish one place from others (Stewart 1970, xxviii), team names were selected to set a school and its community apart from its neighbors. Thousands of cities and towns in the United States proudly display a welcome sign that boasts of its winning teams adjacent to, or sometimes attached to, the official highway sign of the 
community. Wilbur Zelinsky linked this practice with the perceived need to "document uniqueness, to boost [themselves] above the commonplace, to humble the competition" (I988, I). Team names and mascots used in high schools serve a similar purpose, as they were selected by administrators, students, community members, or the local press to characterize a team's style of play or to provide an icon that symbolized a community characteristic, ideology, or another source of pride. They are "often more descriptive, diminutive, humorous, or affectionate [than place names] ... and often used to conjure images of power, strength, fearlessness, and victory over a hapless opponent" (Zeitler and Petzold 200I, 25). These are indeed criteria for many nicknames, but there are some, including the Omaha, Nebraska Benson High Bunnies, that hardly strike fear into an opponent's heart. Their purpose extends beyond the practice of distinguishing schools and communities from one another-team nicknames provide an integral source of place identity for community members and alumni. In theory, the list of possible team names is virtually endless, and this thought lingered as the examination of high school team nicknames commenced.

\section{Methodology}

A dataset of secondary public and private schools used in the United States (not including overseas territories) was purchased from the Clell Wade Coaches Directory, a company that for decades has sold aggregated information about schools, including contact information for their coaches, to college athletic recruiters. The procured data includes school names, address, enrollment, and team names for 20,853 schools open during the 20I5-20I6 academic year. Thirty co-educational schools using distinct names for their girls' teams were included in the dataset and therefore added to the overall count, resulting in a total of 20,883 team names for analysis.

The development of a taxonomy of these names prioritized exhaustive categories that maximized exclusivity. A minimal number of categories covering all team names was desired but the size and breadth of the dataset made exclusivity between them challenging. For example, names referencing aspects of ancient Greek society appear in multiple categories. The process of examining team names for prevailing themes was extended to the development of subcategories within all primary categories except animals, where biological taxonomy was employed, and schools not using team names. Subcategories are discussed in the results section.

In the spirit of developing as thorough a taxonomy as possible, a content analysis of online imagery hosted by school websites, their social media accounts, and affiliated websites, was conducted to identify mascots (Rose 20I6). Thousands of human-based team names comprised the majority of this work. For example, team names like Raiders, Rebels, and Warriors were considered too ambiguous and demanded an examination of their logo and/or mascot to ascertain what type of person was representing these names. Rebels, for 
example, are represented in high schools by likenesses of ancient Greek and Roman fighters, knights, Vikings, colonial soldiers of the American Revolutionary War, and Confederate soldiers of the American Civil War. In most cases, school webpages included a logo of its mascot and the team name could be assigned to a category. Many schools using a controversial mascot, such as a Confederate soldier or an Indigenous person, displayed an unassuming "Rebels" or "Warriors" text logo on their websites to detract attention. However, schoolsponsored social media accounts frequently included photos that revealed the identity of their mascot. When the mascot for an ambiguous team name could not be identified, it was included in the same category as those that were identified but noted as generic. Although time consuming, this methodology produced a database more definitive than the oft-cited list compiled by Massey Ratings (Massey 2017), which is based on team names alone.

\section{Results}

A lengthy examination of prevailing themes among the team names ultimately resulted in seven categories: fauna, flora, humans, inanimate objects and phenomena, deities and spiritual beings, mythological creatures and beings, and schools not using a team name. Collectively, fauna are the most popular team name and mascots in high school athletics ( $\mathrm{I}$ I, 638 schools; $55.73 \%$ of all schools). Humans rank a distant second $(6,945 ; 33.26 \%)$, and inanimate objects and phenomena third (I,OI7; 4.87\%). Deities and spiritual beings (703; $3.37 \%)$, mythological creatures and beings $(428 ; 2.05 \%)$, flora $(54 ; .26 \%)$, and schools choosing not to use team names $(98 ; .47 \%)$ round out the remaining names.

\section{Fauna}

A total of II,638 team names and mascots reference animals, and more than two thirds $(7,946)$ are mammals. Carnivores, a biological order which include the feliformia (cat-like) and caniformia (dog-like) suborders, comprise 6,363 $(80 \%)$ of these mammals. Cats are very popular icons, as $4,2 \mathrm{I} 9$ teams $(20.2 \%$ of all schools) use tigers (965), panthers (840), wildcats (687), lions (626), and other feliforms as mascots. Among the 2,I44 caniforms used include a variety of $\operatorname{dogs}$ (I,II7 in total), with bulldogs (836) and huskies (I50) being the most popular, and bears (482), wolves (287), and wolverines (I4I) also frequently used. Common mascots from other orders of mammals include horses (752), sheep (325), cattle (148), and bison (95).

Neoaves, a biological taxonomic clade consisting of the vast majority of modern birds, comprise $2,877(98.5 \%)$ of the $2,92 \mathrm{I}$ schools using birds as team names or mascots. Raptors, including eagles (I,4I9), hawks (454), and falcons (388) are the most frequently used, with cardinals (293), jays (79), and owls (73) following. 


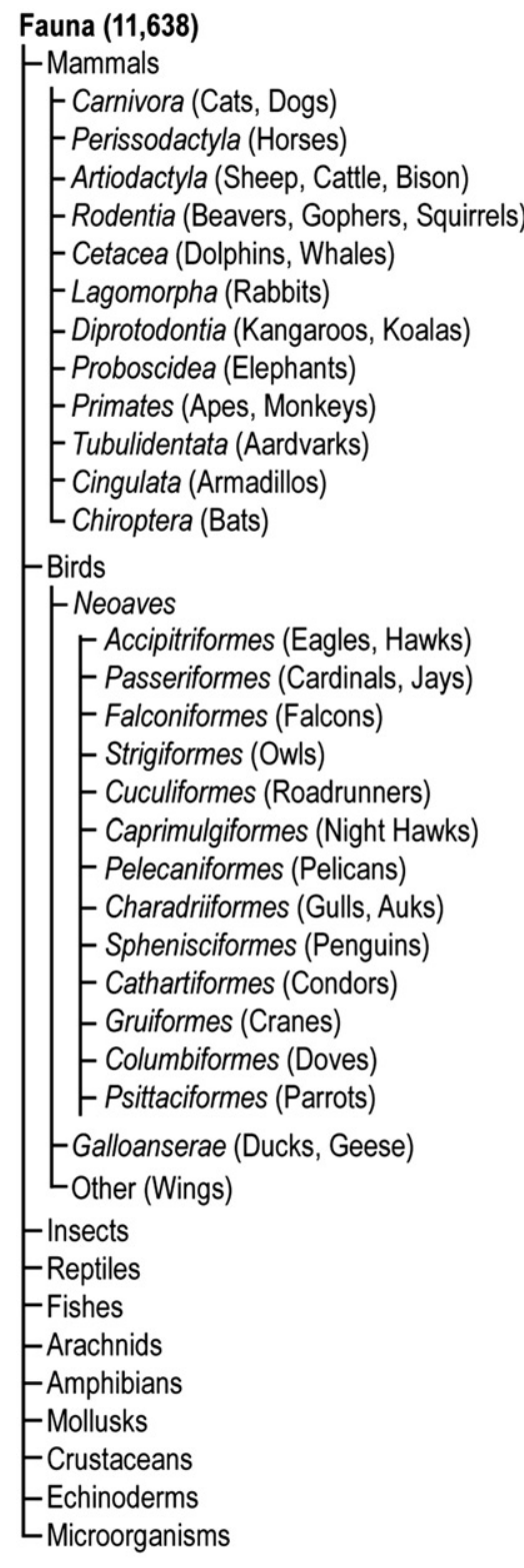

Inanimate Objects and Phenomena $(1,017)$

$\begin{array}{lll}7,946 & \text {-Weather \& Related Natural Phenomena } & 461 \\ 6,363 & \text { - Machines for Transport } & 223\end{array}$

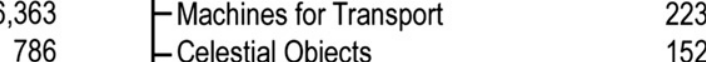

$668-$ Weapons 66

$65 \quad$-Fire-related 53

$19-$ Industrial Machinery 24

$18-$ Non-Industrial Products 17

11 -Magic 5

6 -Atomic Components 4

5 -Feelings 7

3 Letters and Punctuation 2

$2,921 \quad-$ Christian 504

2,877 $\quad 362$

$1,877-$ Saints 128

449 - Angels 14

$388-$ Greek 192

73 -Norse 6

25 -Roman 1

21 Mythological Creatures and Beings (428)

9 -Dragons 169

8 -Ancient Greek or Roman 158

8 - Indigenous 39

4 -Ghosts and Psychopomps 21

4 -Book Characters 12

2 -Wizards and Witches 9

2 -Giants 5

$44 \quad$-Gremlins, Goblins, and Gnomes 6

3 -Sea-based 5

475 Locally Unique 5

177

75

21

Flora (54)

-Leaves 23

-Trees 12

-Seeds 10

-Flowers 5

- Vegetables 3

LFuit 1

No Team Name 98

FIGURE 1. Frequencies of fauna, inanimate objects and phenomena, deities and religious beings, mythological creatures and beings, flora, and no team name taxonomic classifications.

Insects comprise $475(2.3 \%)$ of all team names and mascots used in the United States. Hornets and yellowjackets, wasps known for their aggressive behavior, are used in 434 of them. Reptiles are used in I77 schools, with alligators (9I), rattlesnakes (28), and cobras (26) being the most popular. Sharks (4I) are the most common team name or mascot among 75 schools using fish. 
Others include rays (7), marlins (6), and tarpons (4). The remaining animal team names include 2I arachnids (Scorpions and Spiders), I3 amphibians (including Bullfrogs and Toads), four mollusks (including Snails and Nautilus), two crustaceans (Sandcrabs), two echinoderms (Starfish and Urchin), and one reference to microorganisms, the Biohazards of Life Academy of Health and Bioscience in Oakland, California (Figure I).

\section{Humans}

As sports are widely considered to have metaphorical connections to warfare, it is no surprise that aggression is a prevalent theme among the 6,945 humanbased team names and mascots. No category of names is larger than those referencing people trained to kill, which comprises $2,530(36.43 \%)$ of all teams in this category. Medieval warriors, represented by names such as Knights, Crusaders, Cavaliers, and Lancers, are the most popular lot (I,I6I). Colonial soldiers of the American Revolutionary War (386), Indigenous people represented in the imagery of Warrior team names (382), and Confederate rebels of the American Civil War (I09) are other frequently used representations.

Indigenous people appear again in a category of team names based on the theme of race and ethnicity. Of the I,734 schools in this category, $853(49.2 \%)$ reference them through the use of names such as Indians (403), Braves (I IO), and Chiefs or Chieftains (I06). Ninety-one controversial names refer to the so-called "red" skin of Indigenous people (including 59 Redskins), 89 names reference tribal nation names (such as Mohawks, Utes, and Apaches), and other names include Savages (10), Blackhawks (8), Sachems (6), Maidens (4), and Squaws (2). Greeks of antiquity, including Trojans (358) and Spartans (302), dominate the list of $72 \mathrm{I}$ schools using ancient ethnic group monikers. Gaels (I6), Celts (I2), Saxons (7), and Vandals (6) are among others used. Contemporary ethnic groups are used as mascots in I 60 schools. Scots (75) and Irish (54) comprise $80.6 \%$ of them, but others, including the Dutch (I6), Germans (Io), Turks (I), Arabs (I), Armenians (I), French (I), and Swedes (I) are represented as well.

Individuals with reputations for lawlessness comprise the third largest group of human-based team names and mascots with I,095 schools employing them for names and imagery. A variety of people are represented by the Raiders team name, including knights, soldiers of the Confederate Army, cowboys, and Indigenous people. Pirates, however, are the most frequently referenced people (44I). These swashbucklers, along with their elder seafaring cousins, the Vikings (387), make up $75.6 \%$ of the schools in this category. The western American frontier setting inspires another family of team names, as 92 schools using names such as Outlaws, Renegades, and Rustlers use cowboys and masked horse riders in their logos, and 70 schools represent Marauder and Raider names with Indigenous people.

A group of 658 team names and mascots referencing economic activities often pay homage to local industries or famous residents. Those reflecting work in the 
primary sector, which includes agriculture (206), mining (74), forestry (50), and fishing (I9), outnumber those of other sectors with a total of 349 schools, or $53 \%$ of all schools in this category. Names in these categories include Cowboys (97), Rangers (2I), and Aggies (I6) in agriculture, Miners (3I) and Oilers (I3) in mining, Lumberjacks (23) and Loggers (14) in forestry, and Whalers (5) and Fishermen (3) in fishing. Tertiary-level jobs that include work in transportation (I09), civil service (99), and entertainment (27), are used in 205 schools (3 I.I $5 \%$ of schools in this category). Popular transportation-related team names include Flyers (25), Mariners (19), and Sailors (15). Names and mascots referencing law enforcement, including Rangers (2I), Canadian Mounties (4), politics, including Senators (9), and Ambassadors (7), and entertainment, including Matadors (I6) and Magicians (4) represent trades in this realm. The industrial production of material goods (35), food (19), and transportation infrastructure (I9) are secondary sector jobs found in 74 team names. Railroaders ( 13 ) dominate the transportation construction subcategory, Ironmen (I0), and Boilermakers (5) are common among goods manufacturers, and Packers (9) and Millers (6) are the most frequently used team names commemorating food makers. Seventeen schools, with names such as Surgeons, Engineers, and Chemics, reference employment in the quaternary sector. The last group of I 3 team names in this category, including the Surfriders of Kailua High in Hawail and the Skiers of Aspen High in Colorado, reference local leisure activities.

A small number of schools, 2 Io in total, allude to economic and, by extension, social class in their team names and mascots. References to nobility, including Royals (65), Monarchs (35), and Kings (15) are used in 158 of them. Honorific titles such as Dons (24) are used in 28 schools, and titles tied to specific cultures like Pharaohs, Sultans, and Sheiks, are used in I3. The Delta Kings of Stagg High School in Stockton, California are among four schools claiming "nobility" of a local physical feature. Five schools, including the Millionaires of Williamsport, Pennsylvania and Lenox, Massachusetts note wealthy landowners in the community.

Imagery associated with Pioneers (97), Mountaineers (22), Trailblazers (6), Plainsmen (3), Colonists (I), and Settlers (I) team names are among those representing groups of European colonizers to North America. Of the 148 schools in this distinct category, I I9 $(79.3 \%)$ use a logo of a man wearing a coonskin hat made famous by Davy Crockett, the early white colonizer of the Appalachian frontier (Lofaro I985). Other icons witnessed in this category include weapons such as rifles, bowie knives, and axes (53) and the Conestoga wagon (6).

Of the $\mathrm{I} 35$ schools whose team names or mascots were chosen to honor historical figures, 59 do so for politicians with names such as Senators (9), Governors (7), and Presidents (6). Military leaders from the American Revolution (20), the Confederate Army (I2), Union Army (9), World War II (4), and abroad (4) are referenced in 49 schools.

References to religious titles and groups exist in 69 instances. Catholicism, with names such as Padres, Brothers, and Friars, is most frequent (25). Quakers 


\begin{tabular}{|c|c|c|c|}
\hline umans $(6,945)$ & & & \\
\hline - Race and Ethnicity & 1,734 & - Socioeconomic Class & 210 \\
\hline - Indigenous Peoples & 853 & - Nobility & 171 \\
\hline - Ancient Peoples & 721 & - Titles of Respect & 28 \\
\hline L Contemporary Ethnic Groups & 160 & - Non-Noble Wealth & \\
\hline -Warriors & 2,530 & L "Nobility" of Physiographic Landmark & \\
\hline - Medieval & 1,161 & -Demonyms & 207 \\
\hline - American Revolutionary War & 386 & - Physiographic Demonyms & 107 \\
\hline - Indigenous & 382 & L Political Demonyms & 100 \\
\hline - Ancient & 200 & - Colonizing Peoples & 148 \\
\hline - No Imagery Identified & 138 & -Frontiersman & 119 \\
\hline - Confederate States of America & 109 & - No Imagery Identified & 23 \\
\hline - Weapons, no person & 57 & E Conestoga Wagon & \\
\hline - Ethnic Groups & 34 & L Histarical Figures & \\
\hline - Contemporary & 33 & -Historical Figures & $\begin{array}{l}135 \\
110\end{array}$ \\
\hline Lunassociated Rank Titles & 30 & - Politicians & 119 \\
\hline - Lawless Individuals and Groups & 1,095 & $\begin{array}{l}\text { - Military Leaders } \\
\text {-European Explorers }\end{array}$ & 23 \\
\hline -Early Modern & 441 & $\begin{array}{l}\text {-European Explorers } \\
\text { - Frontiersmen }\end{array}$ & \\
\hline - Medieval & 431 & - Writers & \\
\hline - Western U.S. Frontier & 92 & - Civil Servants & \\
\hline - Indigenous & 70 & - Athletes & \\
\hline - No Imagery Identified & 28 & - Civil Rights Leader & \\
\hline - America Revolutionary War & 15 & - Educator & \\
\hline - Confederate States of America & 12 & - Entertainer & \\
\hline L Ancient & 6 & - Inventor & \\
\hline LEconomic Activities & 658 & L Town Founder & \\
\hline - Primary Sector & 349 & - Characteristics of student athletes & \\
\hline - Tertiary Sector & 205 & Da & \\
\hline - Secondary Sector & 74 & - Religious Individuals and Groups & \\
\hline - Quaternary Sector & 17 & - Colors worn by athletes & 5 \\
\hline L Leisure Activities & 13 & $L_{\text {Body Parts }}$ & \\
\hline
\end{tabular}

FIGURE 2. Frequencies of human taxonomic classifications.

(2I), Calvinists (5), Muslims (2), Pilgrims (2), and other Christian-based team names, including the Fighting Fundamentalists of Fairhaven Baptist Academy in Chesterton, Indiana, round out the rest.

Team names inspired by aspects of local geography exist in 207 schools. These schools incorporate aspects of the local natural or cultural setting (I07) or demonyms (IOO) into their team names. Examples of the first group include the Horicon, Wisconsin Marshmen, the Los Alamos, New Mexico Hilltoppers, the County Seaters of Belvidere, New Jersey, and the Borderites of Blaine, Washington. Demonyms are used as beloved team names of teams in Sand Springs, Oklahoma, home of the Sandites, and in East Hampton, New York, where the Bonackers compete for interscholastic glory.

A small number of schools, 99 in total, use team names that reference the prowess of their students. Thirty-one schools, such as the Bessemer, Michigan 
Speedboys and Speedgirls, refer to quickness. Other names like Giants, Scrappers, and Olympians reflect characteristics of size (I9), fierceness (I6), and overall athleticism (9). A few dozen schools, 57 to be exact, prefer to be known by the color of their jerseys. Variations of red, including maroon and crimson (28), and blue (12) are the most popular among them, but six team names, including the Orabs (Orange and Blacks) of Sheldon, Iowa, reference two colors. Lastly, the smallest and most unusual category in this taxonomy belongs to human body parts - the Hearts of Sacred Heart in Waterbury, Connecticut, the Flaming Hearts of Effingham, Illinois, and the cleverly named Feet of the Webb School in Bell Buckle, Tennessee (Figure 2).

\section{Inanimate Objects and Phenomena}

Just under five percent of all team names, I,OI7 in total, reference an inanimate material object or natural phenomena. Naturally occurring objects and phenomena such as weather, tides, rocks, and minerals comprise 46I of these names. Team names relating to atmospheric phenomena account for 360 of them, including storms in general $(43)$ as well as specific meteorological hazards such as lightning (95), tornadoes (78), hurricanes (6I), thunder (30), cyclones (29), dust devils (9), and extreme temperatures (6). Non-threatening phenomena like rainbows (I), sundogs (I), and the aurora borealis (I) are used by a handful of schools. Natural events and materials occurring on or below the surface of the earth account for Ioo team names, with waves (53), tides (2I), and 22 geologically-related names such as Hematites, Agates, and Artesians responsible for the majority of the group. Blazers (26) and Flames (22) are among the 53 team names using fire as a mascot. A total of I 52 schools have looked beyond Earth in search for a team name, using Comets (9I), Stars (40), and other celestial objects as a result.

Back on terra firma, products of the industrial revolution have inspired hundreds of team names and mascots. Modes of transportation on land (22), water (33), air (58), and space ( I08) are used, as are other products for industrial purposes (24) such as Sparkplugs, Satellites, and Lasers. Weapons such as swords (3I), arrows (I7), hatchets (8), bullets (4), and bombs (3) are used as team names in 66 schools, I 5 of which include visual references to Indigenous weaponry in their logo. Lastly, products made for non-industrial consumption, such as playing cards, textiles, shoes, and food, are used as mascots in I7 schools (Figure I). As the Pretzels of Freeport High School and New Berlin High School in Illinois illustrate, anything can be used as a symbol of school spirit!

\section{Deities and Spiritual Beings}

Although many are visualized in human form, incorporeal religious deities and beings were assessed as a distinct category. They are used as team names and mascots in 703 schools (Figure I). Ancient Roman or Greek deities such as 
Titan (I7I) comprise I92 of these names but are outnumbered by 504 figures typically associated with Christianity, including Devils and Demons (362), Saints ( ( 28), and Angels (I4).

\section{Mythological Creatures and Beings}

A total of 428 schools use mythological creatures and fictional beings as mascots (Figure I). Dragon mascots (I69) are the most popular, but admiration for ancient Greek and Roman culture is evident in the 158 schools using mythological creatures such as the Phoenix (76) and Griffin (60). Indigenous-based names are witnessed though the use of Thunderbirds (36) and Menehunes (2). Twelve schools use fictional characters from books, including William Tell (Marksmen) and the Headless Horseman (Horsemen), as inspiration for team names. Others include beings popular during Halloween such as Ghosts (I9), Wizards (6), Witches (3), Gremlins (4), Goblins (I), and Reapers (I).

\section{Flora}

Fifty-four schools use team names inspired by plants. Twenty-three of these schools use leaves, and the young sprigs of clover known as Shamrocks (2I) are the most prevalent name in this category. Eleven schools using this name are affiliated with the Catholic church, suggesting ties to a local Irish community. Trees (II) such as Maples, Oaks, and Evergreens, and seeds (ro) such as Acorns, Kernels, and Buckeyes are team names. Additional food-based team names appear in this category, as potatoes (Spuds and Russets) and Berries are used in four schools (Figure I). Five schools, including the Ramblers of Rose Bud, Arkansas and the Awesome Blossoms of Blooming Prairie, Minnesota, use a place name-team name association.

\section{Schools not Using Team Names}

A small number of schools, 98 in total, do not use a team name or mascot. Many are charter schools that emphasize academics over athletics, but most are private religious schools that prefer their teams be known by their institutional name rather than an adopted mascot.

\section{Discussion}

Three latent themes emerge from this rich dataset of team names and mascots: convention, bellicosity, and local distinctiveness. A guidebook for selecting a team name is not known to exist, yet most schools adhere to the popular convention of selecting them from a handful of names in two taxonomic categories. The 20 most frequently used team names comprise $53 \%$ of the national total. The top ten, which are used by $37 \%$ of all schools, is comprised of predators 
and people trained to inflict harm. Eagles (I,4I9) top the list, followed by Tigers (93I), Panthers (840), Bulldogs (836), Knights (705), Warriors (70I), Wildcats (687), Lions (626), Cougars (509), and Hawks (454). Historically, collegiate teams such as the Yale Bulldogs and Princeton Tigers influenced high school team name selection (Franks 1982). Alliteration, consonance, or assonance may partially explain this tradition, as they are observed between school and team names in $8,350(40 \%)$ of all schools. The custom of using popular nicknames remains common practice. For instance, the final options for the soon-to-open South Garner High School in North Carolina are the Aggies, Gators, Grizzlies, Raiders, and Titans (Stevens 20I8). Evolution in linguistic standards (Smith I997) and an administrational desire to avoid culturally insensitive names and mascots may also influence name selection.

As is the case among professional and collegiate team names (Franks I982; Nuessel I994), bellicosity is a prevailing theme among team names and mascots used on the fields and in the gymnasia of secondary schools in the United States. Animals known for their aggressive nature, from alligators to yellowjackets, and humans associated with war and lawlessness, whether they are ancient, medieval or modern, seafaring or terrestrial, are employed to both motivate those who wear the jersey and to intimidate their opponents. "Fighting" is used as an adjective for $\mathbf{2} 20$ team names in the dataset, including Indians, Farmers, Frogs, and Mermaids. Trojan and Spartan mascots are exclusively exhibited as warriors, not farmers or artisans of their respective city-states. Highland warriors appear in the imagery of $52 \%$ (39) of the 75 schools using names relating to Scots, and the Hillbilly of Ozark High School in Arkansas wields a shotgun, which is prominently displayed on the school's web page (Ozark Public School District, 20I 8). Thousands of schools commemorate, often controversially, those involved in violent struggles over religion (Crusaders), independence (Patriots), enslavement (Confederate Rebels), and territorial control (Indians). Indigenous people and aspects of their cultures are mascots in I, 373 schools, amounting to I9.8\% of all human-based team names and $6.6 \%$ of all team names. Notably, they are frequently portrayed as hostiles; weapons such as arrows and tomahawks are iconic symbols used in ${ }^{5} 8(39.2 \%)$ of schools using Indians as a team name, and, to reiterate, they are employed as mascots in more than half of Warrior team names $(380)$ and in 70 team names in the outlaw category.

Local distinctiveness describes the desire of a school to be recognized for an aspect of the community's physical or cultural geography, including a hometown landmark, famous son or daughter, historical event, folklore, economic activity, or natural phenomena. The use of distinct team names often evokes a strong sense of place and pride among community members, but it also can become synonymous with the community itself and attract interest from outsiders living hundreds of miles away. Although less common, this theme is evident in every major taxonomic category (less the unnamed, of course). Local pride is particularly prominent in the family of names relating to demonyms and economic activities. Examples abound: from the Zee-Bees of Zion-Benton Township, 
Illinois and the Vineyarders of Martha's Vineyard, Massachusetts to the Punxsutawney, Pennsylvania Chucks, Key West, Florida Conchs, Salem, Massachusetts Witches, and Sishmaref, Alaska Northern Lights. Many team names preserve a historically relevant niche of the local economy that no longer exists. Although the sugar beet refinery in Chinook, Montana closed decades ago, the community's teams still wear their Sugarbeeters apparel with pride. In other cases, a team name captures a glimpse of the popular culture of the period in which the name was selected. Kewpie dolls, which were as popular among children in the second decade of the twentieth century as fidget spinners were to children one century later, are memorialized as the team name and mascot at Hickman High School in Columbia, Missouri. Although the Kewpies name remains is outdated, it has stood uncontested. That is not the case elsewhere, as the frequency of renaming controversial monikers has increased in recent decades. Indigenous team names have been contested in high schools for generations (Taylor 20I3; Zeitler 2008), and recent local-level discussions to retire names which commemorate the Confederacy (Moody 2018) and remove gender exclusive "-men" suffixes (Roemeling 20I8) may represent the next wave of making team names and mascots non-discriminatory and inclusive to all students.

\section{Conclusion}

No country uses as many athletic team names and mascots as the United States. Analysis of the taxonomy of secondary school team names and mascots proposed in this paper sheds light on preferences and values held by society that extend beyond school grounds. A tendency to use conventionally used bellicose names and imagery mirrors the national custom of appearing resolute in character, while at a more intimate scale, many communities celebrate locally distinctive traits and traditions. Many practices revealed here are worthy of deeper examination.

\section{Acknowledgments}

Thanks to Karan Wade for providing the data and to the anonymous reviewers for their feedback.

\section{Disclosure Statement}

No potential conflict of interest was reported by the author.

\section{Funding}

This research was supported by the University of Wisconsin-Eau Claire Faculty Sabbatical Leave Program and George Simpson, Jr. Endowment Fund. 


\section{Bibliography}

Barlow, Sabrina, Betty Burdett, Damien Carey, Urania Fung, Patricia Healy, Tamara Hill, Amanda Huffner, Kelly Rowan, Christina Tonan, and Gary Wilkens. 2005. Mascot mania: Spirit of Texas high schools. Huntsville, TX: Texas Review Press.

Clell Wade Coaches Directory. 20I5. 2015 -20I6 Nationwide School Database. <http://www.coachesdirectory.com $>$ (accessed I June, 20I6).

Franks, Ray. I982. What's in a Nickname? Naming the Jungle of College Athletic Mascots. Amarillo, TX: Ray Franks Publishing Ranch.

Houck, Emerson. 2003. Hoosiers all. Carmel, IN: Hawthorne Publishing.

Houck, Emerson. 20I3. Go Huskies! Beat Felix the Cat! The Story of America's High School Athletic Nicknames and Mascots and What They Reveal about Who We Are. Indianapolis, IN: Bradford House.

Lofaro, Michael A., ed. I985. Davy Crockett: The Man, the Legend, the Legacy, I786-I986. Knoxville, TN: University of Tennessee Press

Massey, Kenneth. 20I7. High School Mascot Count. Massey Ratings Mascot Database. <https://www.masseyratings.com/mascot.php $>$ (accessed Io November, 20I7).

Moody, Jennifer. 2018. "South Albany moves forward on possible Rebel change." Albany DemocratHerald, February 6. <http://democratherald.com/south-albany-moves-forward-on-possible-rebel-change/ article_9a7c6392-ad9a-5cra-9556-ce8d8355faer.html> (accessed I7 February, 2018).

Nuessel, Frank. 1994. Objectionable sports team designations. Names: A Journal of Onomastics 42(2): IOI-II9.

Ozark, Arkansas Public School District. 20I 8. Ozark Public Schools Home Page. <http://www.ozarkhillbillies.org $>$ (accessed 2 January, 20I8).

Roemeling, Alisha. 2018. "South keeps ‘Axe,' lops 'men.'” Eugene Register-Guard, February I 2. <http:// registerguard.com/rg/news/local/3644 I 447-75/in-a-fell-swoop-the-axemen-of-south-eugene-high-schoolbecome-the-axe.html.csp $>$ (accessed I 8 February, 20I 8 ).

Rose, Gillian. 2016. Visual Methodologies: An Introduction to the Researching with Visual Materials. London: SAGE Publications.

Sledge, Rob. 2005. It's a Jungle Out There: Mascot Tales from Texas High Schools. Abilene, TX: State House Press.

Smith, Grant. I997. "School Team Names in Washington State." American Speech 72(2): I72-I82.

Stevens, Nick. 20I8. "South Garner looking for input on mascot." WRAL High School OT, February I 5. $<$ http://www.highschoolot.com/south-garner-looking-for-input-on-mascot/I7344I33/> (accessed 20 February, 20I8).

Stewart, George R. I970. American Place-Names: A Concise and Selective Dictionary for the Continental United States of America. Oxford: Oxford University Press.

Taylor, Michael. 2013. Contesting Constructed Indianness: The Intersection of the Frontier, Masculinity, and Whiteness in Native American Mascot Representations. Lanham, MD: Lexington Books.

Tent, Jan. 20I 5 . Approaches to research in toponymy. Names: A Journal of Onomastics 63(2): 65-74.

Willman, Fred. 2005. Why Mascots Have Tales: The Illinois High School Mascot Manual. Naperville, IL: Mascot Publishing.

Zeitler, Ezra J. 2008. "Geographies of Indigenous-based Team Name and Mascot Use in American Secondary Schools.” PhD diss., University of Nebraska-Lincoln. < https://digitalcommons.unl.edu/geographythesis/ $7 />$ (accessed I December, 20I7).

Zeitler, Micah A., and Petzold, Donald E. 200I. Lions and tigers and bears: The geographical significance of Wisconsin public high school nicknames. Wisconsin Geographer I7: 25-36.

Zelinsky, Wilbur. I988. Where every town is above average: Welcoming signs along America's Highways. Landscape 30 (I): I-IO.

\section{Notes on Contributor}

Dr. Ezra Zeitler is an Associate Professor of Geography in the Department of Geography and Anthropology and an affiliate of the American Indian Studies Program at the University of Wisconsin-Eau Claire. His research interests 
include cultural and historical geographies of North America, cartography, and geographic education. (D) http://orcid.org/0000-0003-3692-3010

\section{ORCID}

(D) http://orcid.org/0000-0003-3692-3010

Correspondence to: Ezra Zeitler, UW-Eau Claire, I05 Garfield Avenue, Eau Claire, WI 54702. Email: zeitleej@uwec.edu. 